\author{
Case Study \\ www.ijrap.net
}

\title{
CLINICAL EFFICACY OF A TRADITIONAL AYURVEDIC COMPOUND ON PEYRONIE'S DISEASE: A CASE STUDY
}

Barik Laxmi Dhar *1, Ratha Kshirod Kumar ${ }^{1}$, Dixit Amit Kumar ${ }^{2}$, Hazra Jayram ${ }^{3}$

${ }^{1}$ Research Officer (Ayurveda), National Research Institute of Ayurvedic Drug Development, Kolkata, CCRAS, Ministry of AYUSH, Government of India, 4-CN Block, Sector V, Bidhannagar, Kolkata, West Bengal, India

${ }^{2}$ Research Officer (Biochemistry), National Research Institute of Ayurvedic Drug Development, Kolkata, CCRAS, Ministry of AYUSH, Government of India, 4-CN Block, Sector V, Bidhannagar, Kolkata, West Bengal, India

${ }^{3}$ Director, National Research Institute of Ayurvedic Drug Development, Kolkata, CCRAS, Ministry of AYUSH,

Government of India, 4-CN Block, Sector V, Bidhannagar, Kolkata, West Bengal, India

Received on: 11/08/15 Revised on: 20/09/15 Accepted on: 07/10/15

\author{
*Corresponding author \\ E-mail: ldbarik1963@yahoo.co.in
}

DOI: $10.7897 / 2277-4343.07252$

\section{ABSTRACT}

Peyronie's disease (PD) is an acquired benign disease of the penis. It is a localized connective tissue disorder, includes the presence of fibrous plaque in the penile shaft, penile curvature, penile pain and erectile dysfunction. There are numerous conventional oral drugs to treat the condition with weak scientific evidence. Due to lack of definite pathophysiology of the disease surgical therapy still represents the gold standard for correction of penile deviation. Phytomedicines and traditional medicines are the first choice to treat male sexual disorders in many developing countries. We report a case of a 45-year-old male who presented with plasticity of penis, difficulty of erection and sexual inability. We treated this case with Kanchanara Guggulu, a classical Ayurvedic formulation and got promising result in reduction in size of plaque, reduction of curvature of the penis, diminution in pain at erection, correction of erection function. Moreover, well structured, standardized, randomized placebo-controlled studies have to be done in future.

KEY WORDS: Kanchanar Guggulu, Peyronie's disease, Sexual dysfunction

\section{INTRODUCTION}

Peyronie's Disease (Penile fibromatosis) is a psychosomatic devastating disease, characterized by painful erections and curvature of the erect penis. It is caused by scar tissue, called plaque, which forms along the length of the penis in the corpora cavernosa. The plaques are detected as a thickened, firm, or hard plaque on the dorsal part of the distal third of penile shaft. The plaques are not visible, and depending on the severity of the condition, the plaques can cause the penis to bend, making sexual intercourse difficult and occasionally painful. The disease may occur in about $1 \%$ to $8 \%$ of men, most frequently in between 40 to 70 years of age ${ }^{1,2}$. The etiology of the disease is not clear. Atheroma formation and penile trauma predisposes to this condition. It is also believed to be a part of autoimmune disease by some researchers ${ }^{3,4,5}$. Symptoms of the disease develop insidiously or may appear overnight. When the penis is soft, no pain is experienced. But, in severe cases, the hardened plaque (which is benign or noncancerous) reduces flexibility, causing pain and forcing the penis to bend or arc during erection ${ }^{6}$. The diagnosis of the disease consists of medical and family history, a physical examination and imaging test ${ }^{7,8}$. The treatment of the disease is challenging and consists of drug like colchicine, potassium para-aminobenzoate, tamoxifen, actetylL-carnitine and Vitamin-E. However, their use is considered offlabel with unconvincing result. Surgical therapy remains the gold standard for patients in the chronic phase of the disease but always put the patient at risk $9,10,11,12$. Medicines prepared based on herbs are gaining an enormous attention now-a-day and about $80 \%$ of global population are rely on it for their primary health care ${ }^{13}$. Phyto-medicines and traditional medicines are also very popular and often used for treating the sexual disorders of men and remains the first choice in many developing countries ${ }^{14}$. The disease is akin with some feature of Dhawjabhanga/ Klaibya and some form of Shukadosa mentioned in Ayurvedic classics. Ayurveda offer many oral and topical medicines to correct the curvature and size of penis. Keeping the etiology and pathophysiology of the disease in view, we plan to treat a case of Peyronie's Disease with Kanchanar Guggulu, a traditional Ayurvedic formulation to assess clinically ${ }^{15}$.

\section{CASE REPORT}

A 40-years male patient of Kolkata metro region, attended Hospital OPD of National Research Institute of Ayurvedic Drug Development, Kolkata, with complain as follows: Unusual angulation of the penile shaft when erect, pain during erections and/or during sex. Patient felt difficulties while on sexual activity and gradually developed plaques with slightly bending since 6 months. Patient did not have any history of injury. On examination he revealed; height $1.7 \mathrm{~m}$, body weight $71 \mathrm{~kg}$ (BMI $24.57 \mathrm{~kg} / \mathrm{m}^{2}$ ), Scarring or plaque palpated at the abnormal bend or angle of the penis, palpable of an indentation of the penis shaft at the site of the plaque or scarring \& inability to have intercourse. He had a treatment history of vitamin 'E' supplementation along with some Non-steroidal antiinflammatory drugs and anti-biotic for 15 days. He found euglycaemic and normotensive. He was habituated to take nonveg diet, and smoking 3-4 cigarette per day. He had an irregular bowel problem with normal bladder and adequate sleeping habits. Family history was not suggestive. 
Manual examination revealed; 10 no. of plaques on ventral part and 7 no. of plaques on dorsal part of the penis by stretching it with one hand and gently compressing the shaft between the fingers and thumb of the other hand. Localized tenderness elicited on superficial palpation and 20 to 30 degree of the penile curvature has been observed and the presence of penile shortening was not remarkably identified. There was no established abnormality disclosed during systemic examination.

\section{Diagnosis}

Patients presenting with circumscribed or diffuse penile indurations are commonly encountered in urological practice. The condition is usually diagnosed by taking proper history of the patient, physical diagnosis, ancillary investigation. i.e. Biopsy, X-ray and Ultrasound (USG).

\section{Laboratory investigation}

A Biopsy sent for study and found to be scar tissue and diagnosed as Peyronie's disease. Human cell antigen, HLA-B7 has not been associated with the disease. USG of penis with high frequency $(7.5-12 \mathrm{MHz})$ linear high transducer suggested penile plaques, seen as focal hyper echoic thickening of the tunica albuginea, exhibiting strong echogenicity with substantial attenuation of the acoustic beam.

\section{Differential Diagnosis}

The differential diagnoses include the following conditions: congenital curvature of the penis, chordee with or without hypospadias, dorsal vein thrombosis, albugineal scar and cavernosal fibrosis secondary to local trauma, chronic inflammation, scleroderma, benign or malignant primary or secondary tumors ${ }^{16}$. The above diseases were differentiated from PD on the basis of Physical characteristics, Clinical diagnosis, laboratory investigations and other special investigations.

\section{Assessment Criteria}

The case was clinically assessed by reduction in size of plaque, reduction of curvature of the penis, diminution in pain at erection, correction of erection function on every week for 6 weeks.

\section{Case conception and treatment selection}

$\mathrm{PD}$, though it is not mentioned in classical Ayurvedic texts, but considering its clinical features, it presumed the vitiation of Kapha-Vata doshas due to presence of plaques, scar tissue and pain. A good number of indigenous compounds have been delineated for the treatment of Vata-Kaphaja disorders and for glandular swelling. Kanchanara Guggulu is one of the best Ayurvedic formulations for the treatment of Goiter and similar conditions. According to Ayurveda it acts on mamsa(flesh) and meda (Body fat) dhatus and have lekhana (scraping) and pachana (increase metabolism in tissues) actions. Kanchnar Guggulu used to reduce accumulated Kapha (Water) in the tissues. It causes disruptions of deep-rooted Kapha dosha (water), maintains the homeostasis of the lymphatic system of body and promotes elimination of toxins. The main ingredient Kanchnara (Bauhinia variegata L.), makes this compound useful for Hypothyroidism, Poly cystic ovarian syndrome, Lipoma, various type of fistula in ano, pilonidal sinuses, elephantiasis, and lymphadenopathy including Hodgkin's disease. It also removes excessive fat from the body. ${ }^{17}$

Ingredients of Kanchanar Guggulu

Kachanara tvak (Stem bark of Bauhinia variegata), Guggul (resin of Commiphora mukul), Haritaki (fruit of Terminalia chebula), Bibhitaka (fruit of Terminalia bellirica), Amalaki (fruit of Emblica officinale), Sunthi (rhizome of Zingiber officinale), Maricha (fruit of Piper nigrum), Pippali (fruit of Piper longum) \& Ela (fruit of Elettaria cardamomum).

Kanchanara guggulu contains tannins, alkaloids- sennoside, ascorbic acid, bioflavonoids, vitamin C, mucilage, essential oilscamphene, eugenol, gingerols, alkaloids- piperine, piperlongumine, Steroids-guggulsterones, that are lipid soluble, and oleoresins.

Treatment plan: The case was prescribed with Kanchanar Guggulu at a dosage of $1 \mathrm{gm}$. thrice daily with Luke warm water after food for 6 weeks and followed up for another two weeks. $\mathrm{He}$ also advised to attend the OPD at an interval of one week.

\section{DISCUSSION}

Based on the schedule of the administration of drug and assessment criteria the case was clinically assessed on every week till the end of 8 weeks. There was reduction in the number and size of plaques observed after 2 weeks of treatment and remarkably reduction noticed at the end of 6 weeks. Pain during erection of penis observed after 1 week of treatment. Curvature of penis reduced remarkably up to 10 degrees after 6 week of treatment. Correction of erection also found improved after 6 weeks of treatment. USG done after 6 weeks of treatment revealed the two corpora cavernosa are homogenous in echo texture and identified as two hypo echoic circular structure. The tunica albuginea is visualized as linear as hyperechoic structure covering the corpora cavernosa.

The various actions attributed by the drug are due to analgesic and anti-inflammatory, anti-microbial, Hypolipidemic, fibrinolytic and anti-tumor activities of various ingredients present in the formulation. The main pathogenesis involved in the PD is atheroma, vasculitis and auto immune factors. The drug might have reversed the exact path way involved in the genesis of disease.

From this investigation, it observed that, there is a significant progress noticed in respect of overall clinical assessment criteria. The indigenous drug Kanchanar Guggulu selected for the case is an important drug mentioned in Ayurveda. The drug has been used and found effective in various conditions like Obesity, Hypothyroidism, Goiter, adenitis, lymphangitis etc, in where the soft tissue of the body is involved. Its efficacy in the PD is not reported earlier. PD is not a common condition found in general practice. However, these patient are primarily visit sexologist and lastly to urologist for a ray of hope. Since surgical grafting is the main stay of treatment for the condition, but can put the patient at risk of development of priapism. Kanchanar Guggulu found effective in the case is safe and no adverse effect level (NOAEL) has been reported so far. The compound formulation helps to reduce inflammatory process and abled to resolve the plaques developed on dorsal and ventral surface of the penis.

\section{Recommendation}

The present study is about the presentation of a single case only. Moreover, a well-structured, standardized, randomized placebocontrolled study is recommended.

\section{ACKNOWLEDGEMENT}

We are thankful to the Director for providing necessary facilities and encouragement to carry out the study. We also thankful to the subject for giving consent to publish the data. 


\section{REFERENCES}

1. Lindsay, M. B., et al. "The incidence of Peyronie's disease in Rochester, Minnesota, 1950 through 1984." The Journal of urology.1991; 146(4):1007-1009.

2. Mulhall JP, Creech SD, Boorjian SA, Ghaly S, Kim ED, Moty A et al. Subjective and objective analysis of the prevalence of Peyronie's disease in a population of men presenting for prostate cancer screening. J Urol.2004;171:2350-3 http://dx.doi.org/10.1097/ 01.ju.0000127744.18878.f1

3. Jarow JP, Lowe FC. Penile trauma: An etiologic factor in Peyronie's disease and erectile dysfunction. J Urol.1997;158:1388-90 http://dx.doi.org/10.1016/S00225347(01)64222-8

4. Ralph DJ, Schwartz G, Moore W, Pryor JP, Ebringer A, Bottazzo GF et al. The genetic and bacteriological aspects of Peyronie's disease. J Urol.1997; 157:291-4. http://dx.doi.org /10.1097/00005392-199701000-00099

5. Chilton CP, Castle WM, Westwood CA, Pryor JP. Factors associated in the etiology of Peyronie's disease. $\mathrm{Br} \mathrm{J}$ Urol.1982;54:748-50 http://dx.doi.org/10.1111/j.1464410X.1982.tb13640.x

6. Pryor JP, Ralph DJ. Clinical presentations of Peyronie Disease. Int J Impot Res.2002; 14:414-7. http://dx.doi.org /10.1038/sj.ijir.3900877

7. Prando D. New sonographic aspects of Peyronie Disease. J Ultrasound Med.2009; 28:217-32

8. Hakim LS. Peyronies disease: An update-the role of diagnostics. Int J Impot Res.2002;14:321-3 http://dx.doi.org /10.1038/sj.ijir.3900871

9. Gur S, Limin M, Hellstrom WJ. Current status and new developments in Peyronie's disease: Medical, minimally invasive and surgical treatment options. Expert Opin Pharmacother.2011;12:931-44 http://dx.doi.org/10.1517 $/ 14656566.2011 .544252$
10. Levine LA, Estrada CR, Storm DW, Matkov TG. Peyronie Disease in younger men characteristics and Treatment Results. J Androl.2003;24:27-32

11. Ralph DJ, Brooks MJ, Bottazzo GF, Pryor JP. The treatment of Peyronie's disease with tamoxifen. $\mathrm{Br} J$ Urol.1992;70:648-51 http://dx.doi.org/10.1111/j.1464410X.1992.tb15836.x

12. Bertolotto M, Coss M, Neumaier C. U/S evaluation of patients with Peyronie disease. In: Bertolotto M, editor. Color Doppler US of the penis. Berlin Germany: SpringerVerlag; 2008:61-9 http://dx.doi.org/10.1007/978-3-54036677-5 12

13. Ratha KK, Mishra SS, Arya JC, Joshi GC. Impact of Climate change on diversity of Himalayan Medicinal Plant: A threat to Ayurvedic system of Medicine. Int. J. Res. Ayurveda Pharm.2012; 3(3): 327-31

14. Gauthaman K,Ganesan AP. The Horomonal effects of Tribulus terrestris and its role in management of male erectile dysfunction- an evaluation using primates, rabbit and rat. Phytomedicine.2008;15(1-2):44-54 http://dx.doi.org /10.1016/j.phymed.2007.11.011

15. Tripathy BN (Ed.). Caraka. 'Caraka Samhita' Sutra Stahna, 30/163-167. Varanasi, India: Choukhamba Sanskrit Sansthan; 2007.

16. Bertolotto M, Coss M, Neumaier C. U/S evaluation of patients with Peyronie disease. In: Bertolotto $\mathrm{M}$, editor. Color Doppler US of the penis. Berlin Germany: SpringerVerlag; 2008. http://dx.doi.org/10.1007/978-3-540-36677-5

17. Sharma PV. Dravyaguna Vijnan, Part-2.Varanasi, India: Choukhamba Bharati Academy; 2005.

\section{Cite this article as:}

Barik Laxmi Dhar, Ratha Kshirod Kumar, Dixit Amit Kumar, Hazra Jayram. Clinical efficacy of a traditional Ayurvedic compound on Peyronie's disease: A case study. Int. J. Res. Ayurveda Pharm. Mar - Apr 2016;7(2):39-41 http://dx.doi.org/10.7897/2277-4343.07252

Disclaimer: IJRAP is solely owned by Moksha Publishing House - A non-profit publishing house, dedicated to publish quality research, while every effort has been taken to verify the accuracy of the content published in our Journal. IJRAP cannot accept any responsibility or liability for the site content and articles published. The views expressed in articles by our contributing authors are not necessarily those of IJRAP editor or editorial board members. 